\title{
Growth and Inequality: \\ A Demographic Explanation
}

by

Kazutoshi Miyazawa

Nanzan University and London School of Economics

Discussion Paper

No. DARP 75

July 2005
Distributional Analysis Research Programme The Toyota Centre Suntory and Toyota International Centres for Economics and Related Disciplines London School of Economics Houghton Street London WC2A 2AE 


\begin{abstract}
This paper investigates the relationship between growth and inequality from a demographic point of view. In an extended model of the accidental bequest with endogenous fertility, we analyze the effects of a decrease in the old-age mortality rate on the equilibrium growth rate as well as on the income distribution. We show that the relationship between growth and inequality is at first positive and then may be negative in the process of population aging. The results are consistent with the empirical evidence in some developed countries.
\end{abstract}

JEL Classification: D31, J13, O41

Keywords: Inequality, Growth, Fertility, Accidental bequest 


\section{Distributional Analysis Research Programme}

The Distributional Analysis Research Programme was established in 1993 with funding from the Economic and Social Research Council. It is located within the Suntory and Toyota International Centres for Economics and Related Disciplines (STICERD) at the London School of Economics and Political Science. The programme is directed by Frank Cowell. The Discussion Paper series is available free of charge and most papers are downloadable from the website. To subscribe to the DARP paper series, or for further information on the work of the Programme, please contact our Research Secretary, Sue Coles on:

Telephone: UK+20 79556678

Fax: $\quad$ UK+20 $\quad$ s.9556951

Email: $\quad$ s.coles@lse.ac.uk

Website: http://sticerd.lse.ac.uk/DARP 


\section{Introduction}

Faced with the rapid trend of population aging, some developed countries suffer from two serious economic problems: a slowdown of growth rate and inter- and intra- generational income inequalities.

Emphasizing that distributional changes are an important part of the economic history of the twentieth century, Atkinson (1999) shows that the distribution of earnings in the UK is not well described by 'stability' (Figure 1, p. 59). While the bottom decile has been almost constant, around 55 per cent of the median since the late 1970s, the top decile has increased from 167 per cent of the median in 1977 to 191 per cent in 1999. The significant change at the top of the distribution worsens intragenerational income inequality. According to the IFS estimates, the Gini coefficient has increased by 10 percentage points since the late 1970s (Figure 2) ${ }^{1}$.

OECD (1998) presents some evidence that intergenerational income inequality becomes worsened. In OECD countries as a whole, the per capita income of the household where the head is aged 65 or above has reached some 84 per cent of the average income of all age groups in the mid 1990s, which is the same level as for the household where the head is aged 30 or less. However, the income of the older age group has increased by 3.4 per cent for some ten years, while the income of the younger age group has decreased by 7.4 per cent (Table IV.1, p. 57). If the trends continue, the income difference will be seriously worsened.

This paper attempts to construct an analytical model consistent with the phenomena observed in Atkinson (1999) and OECD (1998) and to analyze the relationship between growth and inequality in a context of population aging. We use an extended model of the accidental bequest (Abel, 1985) not only because the model highlights the important role of intergenerational transfers in the capital market ${ }^{2}$, but also because wealth explains non-negligible factors of inheritance inequality ${ }^{3}$. One of the main extensions is to endogenize the fertility rate. It has two merits. First, it gives the relationship between the mortality decline and the fertility decline, which is commonly observed in developed countries. Second, it enables us to examine intragenerational inequality analytically in the accidental bequest model, which is typically complicated by wealth accumulation. With some assumptions, we have a two-class economy in which a higher income group receives some bequests from the previous generation and a lower income group receives nothing.

We use an old-age mortality rate as an explanatory variable because our interest is mainly in the phenomena in developed countries, where old-age mortality has been improved and is forecast to be further improved while, at the same time, the economic impact of the infant mortality rate is fairly small.

There seems to be room for argument about what kind of index we should use in order to evaluate income inequalities. To avoid discretionary use as much as possible, we use three inequality indices. First, we compare the income

\footnotetext{
${ }^{1}$ The distribution of wealth is more concentrated and skewed to higher income groups than the distribution of earnings. See, for example, Castañeda, Díaz-Giménez, and Ríos-Rull (2003) and De Nardi (2005).

${ }^{2}$ In an influential study, Kotlikoff and Summers (1981) estimate that a large fraction of the US capital stock was attributable to intergenerational transfers.

${ }^{3}$ Bowles and Gintis (2002) decomposes a correlation between parent income and offspring income, which is estimated 0.32 , into several causal channels. Wealth accounts for 0.12 , which is much higher than schooling (0.07), race (0.07), and IQ (0.04).
} 
difference between the rich and the poor. Second, we use the Gini coefficient. These indices can capture the intragenerational inequality. Finally, we use a conventional index for the optimal income distribution based on a BenthamLerner social welfare function. It enables us to measure the intergenerational inequality, although social welfare itself is somewhat discretionary.

We have two analytical results. First, in earlier phases of population aging, a decrease in the old age mortality rate encourages economic growth and worsens inter- and intra- generational inequalities. Thus, we have a positive relationship between inequality and growth. Second, in the process of population aging, the mortality decline may be harmful to economic growth. Also income inequalities are worsened in some circumstances. In this phase, we have a negative relationship between inequality and growth.

The mechanism of our model is simple. Assuming homothetic preferences, the marginal propensity to save out of wealth would be constant. When unearned income such as a bequest is added to full income, the saving rate, which is measured by the ratio of saving to wage income, increases with the amount of bequests. Since the higher income group receives some bequests and the lower income group receives nothing, the former has a higher propensity to save out of wage income than the latter. In this setting, population aging has two effects on the aggregate saving rate. First, it increases the aggregate saving rate directly by increasing precautionary saving for the prolonged retirement and indirectly by increasing the accidental bequest. The bequest-wage ratio is relevant because the higher income group has a higher propensity to save. Second, population aging reduces the frequency of accidental bequests, which implies that the population share of the higher income group decreases. This distributional effect decreases aggregate saving. Whether the aggregate saving rate increases in the process of population aging depends on the magnitude of the positive propensity effect and the negative distributional effect. In the earlier phases where the old age mortality rate is relatively high, the positive propensity effect is dominant because a decrease in the mortality rate boosts the bequest-wage ratio as well as the marginal propensity to save out of wealth. In this case the aggregate saving rate increases. In the process of population aging, however, the negative distributional effect may be dominant in a case where the physical capital externality is relatively weak. If it is the case, we have a hump-shaped pattern of the growth rate with respect to the old-age mortality rate ${ }^{4}$.

Population aging also has a significant impact on the income distribution. Assume that intragenerational income inequality is measured by the income difference between the higher and the lower income group. In the process of population aging, the higher income group becomes richer and the lower income group remains in the previous relative position because the increase in the bequest-wage ratio is relevant only to the higher income group. The steady increase in the top decile and the stagnancy in the bottom decile are consistent with the phenomena which has taken place since the late 1970s in the UK (Atkinson, 1999). Combining the effects of population aging on the growth rate

\footnotetext{
${ }^{4}$ In an endogenous growth model à la Romer (1986), the growth rate of per capital income is related positively to the aggregate saving rate and negatively to the fertility rate. It can be shown below that the fertility rate decreases with population aging, which is well known as the demographic transition in the modern growth regime (Galor and Weil (1998, 2000)). Combining the saving effect and the fertility effect, we can derive a hump-shaped pattern of the growth rate.
} 
and income inequality, we observe that the relationship is at first positive and then negative in the process of population aging.

The remainder of the paper is structured as follows. Section 2 compares and contrasts our paper with the related literature. Section 3 introduces the basic model and derives the equilibrium condition on a balanced growth path. The effect of population aging on the growth rate is examined. Section 4 examines how population aging affects the intra- and inter-generational income inequalities. Combining the results in section 3 and 4 , we can discuss a dynamic relationship between inequality and growth from a demographic point of view. The final section concludes the paper.

\section{Related literature}

Theoretically, this paper is relevant to the following two important issues. First, it gives an answer to the question whether income inequality is positively or negatively related to the income level in a conventional growth model, or to the equilibrium growth rate in an endogenous growth model. Many papers assume that income inequality arises from capital market imperfection ${ }^{5}$. Special attention has been paid to a borrowing constraint on education loans since Galor and Zeira (1993) demonstrate the important role of the initial distribution of wealth in macroeconomics (Galor and Zang (1997), Owen and Weil (1998), Dahan and Tsiddon (1998), Hazan and Berdugo (2002), and Checchi and García-Peñalosa (2004) among others). With a convex technology of human capital formation, these models can generate multiple equilibria, which implies that there exists a threshold level of the initial wealth. The initial distribution of wealth matters because it determines the threshold level. It can be shown in some circumstances that a higher equilibrium becomes a unique steady state if the variance of the distribution is relatively small. If it is the case, we can observe a negative relationship between the income level and income inequality. Focusing on annuity market imperfection, this paper demonstrates a non-linear relationship between growth and inequality from a demographic point of view ${ }^{6}$. It seems plausible to take the recent change in wealth distribution in developed countries as an attribute of the demographic change. This demographic change matters because it determines both the wealth distribution and the growth rate.

Second, this paper gives an answer to the question of how much the distributional consideration is relevant to the growth effect of population aging. Representative agent models have rather optimistic conclusions. Ehrlich and Lui (1991) show that a stagnant equilibrium can take off into a growth equilibrium when either the young-age or old-age mortality rate decreases. Endogenizing the schooling time, Kalemli-Ozcan, Ryder, and Weil (2000) show that an increase in life expectancy has a positive impact on human capital formation as well as aggregate consumption. In the endogenous growth model à la Lucas (1988) which has an actuarially fair annuity market, Zhang and Zhang (2001) show that a decrease in the old age mortality rate encourages economic growth both by increasing human capital investment and by decreasing the fertility rate.

\footnotetext{
${ }^{5}$ See, for example, Bénabou (1996).

${ }^{6}$ Some papers conclude in the other contexts that the relationship between growth and inequality depends on the stage of economic development (see Aghion and Bolton (1992), Galor and Tsiddon (1997), and Banerjee and Duflo (2000)).
} 
Similar results are also obtained in Yakita (2001). On the other hand, some papers recognize that the growth effect of population aging may be negative in the accidental bequest model. Assuming a constant population, Fuster (1999), Cipriani (2000), and Zhang, Zhang, and Lee (2003) show that the growth rate is hump-shaped with respect to the mortality rate. It can be inferred that the distributional consideration behind the result is relevant to the growth effect of population aging. The model of this paper is different from Fuster (1999) and Zhang, Zhang, and Lee (2003) in that it endogenizes the fertility rate, although the motivation itself is far different. Our model is similar to Zhang and Zhang (2001), which elaborates on how to analyze alternative bequest motives which affect the rates of fertility, saving, and growth as well as the effect of pay-asyou-go social security. It is of great benefit to our model construction, but the analytical focus is far different. Our focuses are not only on the growth effect of population aging but also on the income distribution.

\section{Model}

\subsection{Household}

We use a two-period overlapping generations model with uncertain lifetime. An individual newly born into the economy lives for two periods at most. In the first period of life, he works, consumes, saves, and has children. At the end of the period, he faces a probability of dying, $p \in(0,1)$. This probability is common knowledge within the same generation and across different generations. We assume that the longevity risk cannot be hedged by annuity insurance. If he survives into the second period, he consumes the fruits of his saving without leaving bequests. If he dies, he leaves unintended bequests equally to his children. Individuals in the same generation are differentiated by their ancestors' longevity history because the unintended bequest makes their initial assets heterogeneous. Denoting by $i(i=0,1,2, \ldots)$ the number of successive ancestors who died in the first period of life, the population share of type $i$, who belongs to group $i$, is given by $(1-p) p^{i} .{ }^{7}$

The expected utility function of type $i$ born in period $t$ is represented by

$$
u_{t}(i)=\ln c_{1 t}(i)+(1-p) \alpha_{1} \ln c_{2 t+1}(i)+\alpha_{2} \ln n_{t}(i)
$$

$c_{1}$ and $c_{2}$ stand for young-age and old-age consumption, respectively. $n>0$ stands for the number of children. $\alpha_{1}$ is a private discount factor, and $\alpha_{2}$ is a preference parameter attached to the number of children. by

The budget constraints in the first and second period are respectively given

$$
\begin{aligned}
b_{t}(i)+w_{t} l_{t}(i) & =c_{1 t}(i)+s_{t}(i) \\
\left(1+r_{t+1}\right) s_{t}(i) & =c_{2 t+1}(i)
\end{aligned}
$$

\footnotetext{
${ }^{7}$ Precisely, the total number of types in period $t$ is equal to $t+1$, which must be a finite number. Assume that the model economy starts at period 1. Assume also that a fraction $(1-p)$ of individuals who are born at the beginning of period 1 do not receive bequests (type 0 ) and that the rest of the generation receive some bequests (say, type 1). In the next period, the population share of types 0,1 , and 2 are respectively given by $1-p,(1-p) p$, and $p^{2}$. In the same way, the population share of type $i(i=0,1, \ldots t-1)$ in period $t$ is $(1-p) p^{i}$, and that of type $t$ is given by $p^{t}$. However, the economic impact of type $t$ in period $t$ may be measure zero if $t$ is sufficiently large.
} 
where $l$ and $s$ stand for working time and savings, respectively. $w$ is a wage rate and $r$ is an interest rate. $b$ stands for bequests received at birth. Since parents of type 0 do not leave bequests, $b_{t}(0)=0$.

The cost of having one child is represented by a rearing time cost, $v$. Normalizing available time in the first period to unity, the time constraint is given by

$$
l_{t}(i)+v n_{t}(i)=1
$$

The optimization problem is to maximize (1) subject to (2), (3), and (4).

Solving it, we have the demand for children,

$$
n_{t}(i)=\frac{\alpha_{2}\left[1+\hat{b}_{t}(i)\right]}{v\left[1+\alpha_{1}(1-p)+\alpha_{2}\right]}
$$

where $\hat{b}_{t}(i)$ stands for a bequest-wage ratio,

$$
\hat{b}_{t}(i) \equiv \frac{b_{t}(i)}{w_{t}}
$$

The labor supply is given by

$$
l_{t}(i)=1-\frac{\alpha_{2}\left[1+\hat{b}_{t}(i)\right]}{1+\alpha_{1}(1-p)+\alpha_{2}}
$$

The young-age consumption and the savings are respectively given by

$$
\begin{aligned}
c_{1 t}(i) & =\frac{\left[1+\hat{b}_{t}(i)\right] w_{t}}{1+\alpha_{1}(1-p)+\alpha_{2}} \\
s_{t}(i) & =\frac{(1-p) \alpha_{1}\left[1+\hat{b}_{t}(i)\right] w_{t}}{1+\alpha_{1}(1-p)+\alpha_{2}}
\end{aligned}
$$

With probability $1-p$, he survives into the second period of life and consumes the fruits of his saving,

$$
c_{2 t+1}(i)=\left(1+r_{t+1}\right) s_{t}(i)
$$

With probability $p$, he dies at the end of the first period and leaves bequests to his children. Since they belong to group $i+1$, the bequest per child, $b_{t+1}(i+1)$, is represented by

$$
n_{t}(i) b_{t+1}(i+1)=\left(1+r_{t+1}\right) s_{t}(i)
$$

Substituting (5) and (8) into (10), we have

$$
b_{t+1}(i)=(1-p) v \frac{\alpha_{1}}{\alpha_{2}} w_{t}\left(1+r_{t+1}\right) \equiv b_{t+1}
$$

for any $i \geq 1$. Equation (10) shows that $b_{t+1}(i+1)$ is proportional to $s_{t}(i) / n_{t}(i)$. Equations (5) and (8) show that the impact of $\hat{b}_{t}(i)$ on fertility and saving are similar to one another, given that the utility function is log-linear and the cost function is linear. Thus, we know that $b_{t+1}(i+1)$ is independent of $b_{t}(i)$, which implies that all individuals except for type 0 receive the same amount of bequests. Although the assumptions seem somewhat stringent, they drastically 
simplify the analysis of the accidental bequest model, which is typically complicated by wealth accumulation. They enable us to have analytical solutions to examine the intergenerational income inequality between the young-age savers and the old-age dissavers, as well as the intragenerational income inequality between the poor (type 0 ) and the rich (type $i \geq 1$ ) in the process of population aging $^{8}$.

From an individual viewpoint, a decrease in the old age mortality rate increases the accidental bequest because people are willing to increase precautionary savings. It worsens intragenerational inequality between the rich and the poor. Since the rich have a larger propensity to save than the poor, the mortality decline would contribute to capital formation.

From the macroeconomic viewpoint, however, the mortality decline decreases the population share of the rich. Therefore it depends on the magnitude of the positive propensity effect relative to the negative share effect whether population aging contributes to capital formation or not.

\subsection{Aggregation}

The population share of group 0 is $1-p$ and that of the other groups $i \geq 1$ is $\sum_{i=1}^{\infty}(1-p) p^{i}=p$. Denoting by $N_{t}$ the total population born at period $t$, the aggregate variables are respectively given as follows.

The bequest transferred to generation $t$

$$
B_{t}=b_{t}(0)(1-p) N_{t}+b_{t} p N_{t}=p \hat{b}_{t} w_{t} N_{t}
$$

Average fertility rate

$$
\begin{aligned}
n_{t} & =n_{t}(0)(1-p)+n_{t}(i) p \\
& =\frac{\alpha_{2}\left(1+p \hat{b}_{t}\right)}{v\left[1+\alpha_{1}(1-p)+\alpha_{2}\right]}
\end{aligned}
$$

Aggregate labor supply

$$
\begin{aligned}
L_{t} & =l_{t}(0)(1-p) N_{t}+l_{t}(i) p N_{t} \\
& =\left[1-\frac{\alpha_{2}\left(1+p \hat{b}_{t}\right)}{1+\alpha_{1}(1-p)+\alpha_{2}}\right] N_{t}
\end{aligned}
$$

Young-age consumption

$$
\begin{aligned}
C_{1 t} & =c_{1 t}(0)(1-p) N_{t}+c_{1 t}(i) p N_{t} \\
& =\frac{1+p \hat{b}_{t}}{1+\alpha_{1}(1-p)+\alpha_{2}} w_{t} N_{t}
\end{aligned}
$$

Aggregate saving

$$
\begin{aligned}
S_{t} & =s_{t}(0)(1-p) N_{t}+s_{t}(i) p N_{t} \\
& =\frac{(1-p) \alpha_{1}\left(1+p \hat{b}_{t}\right)}{1+\alpha_{1}(1-p)+\alpha_{2}} w_{t} N_{t}
\end{aligned}
$$

\footnotetext{
${ }^{8}$ If the assumptions are relaxed, the population distribution becomes complex since the fertility rate depends on the wealth accumulation. One can incorporate fertility decision into a computational general-equilibrium method such as Huggett (1996) and Huggett and Ventura (2000), although it is beyond the scope of the paper.
} 
A fraction $(1-p)$ of the savings is consumed by old-age people,

$$
\begin{aligned}
C_{2 t+1} & =(1-p)\left(1+r_{t+1}\right) S_{t} \\
& =\frac{(1-p)^{2} \alpha_{1}\left(1+p \hat{b}_{t}\right)}{1+\alpha_{1}(1-p)+\alpha_{2}} w_{t} N_{t}\left(1+r_{t+1}\right),
\end{aligned}
$$

and the rest is transferred to the next generation as accidental bequests,

$$
\begin{aligned}
B_{t+1} & =p\left(1+r_{t+1}\right) S_{t} \\
& =\frac{p(1-p) \alpha_{1}\left(1+p \hat{b}_{t}\right)}{1+\alpha_{1}(1-p)+\alpha_{2}} w_{t} N_{t}\left(1+r_{t+1}\right)
\end{aligned}
$$

Note that (18) is equivalent to (12) given that (11) is satisfied.

\subsection{Production}

Aggregate production is represented by a constant-returns-to-scale production function,

$$
Y_{t}=F\left(K_{t}, A_{t} L_{t}\right)
$$

where $Y, K$, and $L$ stand for output, capital stock, and labor, respectively. $A$ stands for the labor-augmenting stock of knowledge.

Following the idea of Arrow (1962), Romer (1986), and Grossman and Yanagawa (1993), we specify the stock of knowledge as

$$
A_{t}=\frac{1}{a} \frac{K_{t}}{L_{t}}
$$

where $a>0$ stands for the strength of externality. This specification may well fit for the developed countries concerned because they could stay on the technology frontier.

Assuming competitive factor markets, we have

$$
\begin{aligned}
r_{t} & =r=f^{\prime}(a) \\
w_{t} & =\eta k_{t}
\end{aligned}
$$

where $k_{t}=K_{t} / L_{t}$ stands for the capital labor ratio, $f()=.F(., 1)$ is the production function per effective labor ${ }^{9}$, and

$$
\eta \equiv \frac{f(a)}{a}-f^{\prime}(a)>0
$$

Since the social rate of return of capital is $\partial Y_{t} / \partial K_{t}=r+\eta, \eta$ stands for the magnitude of the externality related to knowledge accumulation.

\subsection{Equilibrium}

The demographic pattern follows

$$
N_{t+1}=n_{t} N_{t}
$$

${ }^{9}$ We assume $f^{\prime}>0, f^{\prime \prime}<0, f(0)=0, \lim _{k \rightarrow+0} f^{\prime}(k)=+\infty$, and $\lim _{k \rightarrow \infty} f^{\prime}(k)=0$. 
The capital market clears when

$$
K_{t+1}=S_{t}
$$

The goods market clears when

$$
K_{t}+Y_{t}=C_{1 t}+C_{2 t}+K_{t+1}
$$

which can be derived from Walras' law.

The per capita growth rate is defined by

$$
g_{t} \equiv \frac{K_{t+1} / N_{t+1}}{K_{t} / N_{t}}-1
$$

From (20), (21), and (22), we have

$$
1+g_{t}=\frac{\eta \hat{s}_{t}}{n_{t}}
$$

where $\hat{s}_{t}$ stands for a saving rate which is defined by the ratio of aggregate saving to wage income ${ }^{10}$,

$$
\hat{s}_{t} \equiv \frac{S_{t}}{w_{t} L_{t}}
$$

Equation (24) shows that the growth rate is related positively to the saving rate and negatively to the fertility rate. Substituting (14) and (16) into (25), we have

$$
\hat{s}_{t}=\frac{\alpha_{1}(1-p)\left(1+p \hat{b}_{t}\right)}{1+\alpha_{1}(1-p)-\alpha_{2} p \hat{b}_{t}}
$$

From (14) and (20), the wage growth rate is given by

$$
\frac{w_{t+1}}{w_{t}}=\left(1+g_{t}\right) \frac{1+\alpha_{1}(1-p)-\alpha_{2} p \hat{b}_{t}}{1+\alpha_{1}(1-p)-\alpha_{2} p \hat{b}_{t+1}}
$$

Dividing both side of (11) by $w_{t+1}$, and using (27), we have

$$
\hat{b}_{t+1}=\frac{\alpha_{1}}{\alpha_{2}} v(1-p) \frac{1+r}{1+g_{t}} \frac{1+\alpha_{1}(1-p)-\alpha_{2} p \hat{b}_{t+1}}{1+\alpha_{1}(1-p)-\alpha_{2} p \hat{b}_{t}}
$$

The dynamics of $g_{t}, n_{t}, \hat{s}_{t}$, and $\hat{b}_{t}$ are characterized by (13), (24), (26), and (28). Since the aggregate production is $A K$ technology, an equilibrium jumps immediately to a new equilibrium when the mortality rate changes. To show this, substituting (13) and (26) into (24), we can solve the growth rate as a function of $\hat{b}_{t}$,

$$
1+g_{t}=\eta \frac{\alpha_{1}}{\alpha_{2}} v(1-p) \frac{1+\alpha_{1}(1-p)+\alpha_{2}}{1+\alpha_{1}(1-p)-\alpha_{2} p \hat{b}_{t}}
$$

\footnotetext{
${ }^{10}$ The definition of the saving rate follows Zhang and Zhang (2001). From (20) and (22), the saving rate is proportional to the aggregate saving rate, $K_{t+1} / Y_{t}$. Note that $\hat{s}_{t}$ may exceed one if the share of bequest in the household income is relatively large.
} 
Other things being equal, the growth rate is increasing in the bequest-income ratio. Substituting (29) into (28), the bequest-income ratio is determined by a single equation,

$$
\hat{b}_{t+1}=\frac{1+r}{\eta} \frac{1+\alpha_{1}(1-p)-\alpha_{2} p \hat{b}_{t+1}}{1+\alpha_{1}(1-p)+\alpha_{2}}
$$

which implies that $\hat{b}_{t+1}$ is adjusted to a new steady state when $p$ changes in period $t+1$.

On a balanced growth path (BGP), per capita variables grow at a constant rate of $g$, and aggregate variables grow at a constant rate of $g+n$. The BGP condition requires that $g, n, \hat{s}$, and $\hat{b}$ are constant. From (13), (24), (26), and (28), the equilibrium on the BGP is characterized by the following four equations:

$$
\begin{aligned}
n & =\frac{\alpha_{2}(1+p \hat{b})}{v\left[1+\alpha_{1}(1-p)+\alpha_{2}\right]} \\
1+g & =\frac{\eta \hat{s}}{n} \\
\hat{s} & =\frac{\alpha_{1}(1-p)(1+p \hat{b})}{1+\alpha_{1}(1-p)-\alpha_{2} p \hat{b}} \\
\hat{b} & =\frac{\alpha_{1}}{\alpha_{2}} v(1-p) \frac{1+r}{1+g}
\end{aligned}
$$

In order to make the result clear, we use an alternative parameter related to the knowledge externality,

$$
\beta \equiv \frac{\eta}{1+r}=\frac{f(a) / a-f^{\prime}(a)}{1+f^{\prime}(a)}
$$

A higher $\beta$ corresponds to a higher knowledge externality. ${ }^{11}$

Solving (13'), (24'), (26'), and (28'), we have

$$
\begin{aligned}
n & =\frac{1}{v} \frac{\alpha_{2}(\beta+p)}{\beta\left[1+\alpha_{1}(1-p)\right]+\alpha_{2}(\beta+p)} \\
\hat{b} & =\frac{1+\alpha_{1}(1-p)}{\beta\left[1+\alpha_{1}(1-p)\right]+\alpha_{2}(\beta+p)} \\
\hat{s} & =\frac{\alpha_{1}(1-p)(\beta+p)}{\beta\left[1+\alpha_{1}(1-p)\right]} \\
1+g & =\frac{\alpha_{1}}{\alpha_{2}} \eta v(1-p)\left[1+\frac{\alpha_{2}(\beta+p)}{\beta\left[1+\alpha_{1}(1-p)\right]}\right]
\end{aligned}
$$

The comparative statics analysis gives the following propositions:

Proposition 1 When the mortality rate decreases, the fertility rate decreases and the bequest-wage ratio increases.

Proof. Differentiating (30) and (31) with respect to $p$, we have $d n / d p>0$ and $d \hat{b} / d p<0$.

\footnotetext{
${ }^{11} \beta$ corresponds to $z$ in Zhang and Zhang (2001).
} 
The former result illustrates the demographic transition in developed countries. Similar results are obtained in several altruistic bequest models. The latter result is related to the precautionary saving. When their lifetime is prolonged, people increase savings for their retirement, which in turn increases accidental bequests. The rich become richer, and the poor remain poor in the process of population aging.

Proposition 2 When the mortality rate decreases, the saving rate first increases and then decreases if and only if

$$
\beta<\beta_{s} \equiv 1+\alpha_{1}
$$

Proof. See Appendix.

Proposition 2 says that the saving rate is hump-shaped with respect to the mortality rate if the externality is weak. As is well-known, a decrease in the old age mortality rate increases the propensity to save at individual levels. However, the other effect, a distributional effect, should be recognized because agents are born with heterogeneous assets. We know that the rich have a larger propensity to save than the poor, and that the population share of the rich decreases with the mortality decline. The saving rate falls if the negative share effect dominates the positive propensity effect, which may occur when the externality is weak and the level of the mortality rate has been low enough. Our model contrasts with the altruistic bequest models in this respect, which arises from the existence of heterogeneous savers.

Proposition 3 When the mortality rate decreases, the growth rate first increases and then decreases if and only if

$$
\beta<\beta_{g} \equiv \frac{\alpha_{2}\left(1+\alpha_{1}\right)}{\left(1+\alpha_{1}\right)^{2}+\alpha_{2}}
$$

Proof. See Appendix.

In contrast with Fuster (1999) and Zhang, Zhang, and Lee (2003), the mortality rate which maximizes the growth rate does not coincide with the one that maximizes the saving rate because fertility is endogenous. ${ }^{12}$ Proposition 1 states that the fertility rate monotonically decreases according to the mortality decline. This demographic change promotes per capita income growth. Proposition 2 states that the saving rate first increases then may decrease according to the mortality decline. Thus, in earlier phases of population aging, the mortality decline encourages economic growth both by the fertility and saving effect. In the process of population aging, however, the mortality decline becomes harmful to economic growth if the negative saving effect dominates the positive fertility effect. From (34) and (35), we know that $\beta_{g}<\beta_{s}$, which implies that the hump-shaped pattern of the growth rate can be observed if the externality is weak enough to make the negative saving effect dominate the positive fertility effect.

\footnotetext{
${ }^{12}$ Zhang, Zhang, and Lee (2003) derives a similar hump-shaped pattern in a Lucas-type endogenous growth model. The reason is that it is the aggregate saving rate that determines the growth rate if the public schooling is not controlled (p.91).
} 


\section{Growth and inequality}

This section examines a dynamic relationship between growth and inequality in the context of population aging. We use two alternative indices to measure the intragenerational inequality: income difference between the rich and the poor, and the Gini coefficient. To measure the intergenerational inequality, we use a criterion for the optimal income distribution based on a BenthamLerner social welfare function. When the mortality rate decreases, we show that (i) the income difference between the two groups monotonically increases; (ii) the Gini coefficient first increases and then decreases; and (iii) the index of intergenerational inequality monotonically increases.

\subsection{Intragenerational inequality}

\subsubsection{Income difference between the rich and the poor}

Since the full income of the rich is $(1+\hat{b}) w_{t}$ and that of the poor is $w_{t}$, the income difference can be measured simply by the bequest-wage ratio, $\hat{b}$. We know that it increases monotonically with the mortality decline (Proposition 1 ), and that the growth rate first increases and then may decrease (Proposition 3). Therefore we have a positive relationship between growth and inequality in the earlier phases, and the relationship can be negative in the process of population aging.

\subsubsection{Gini coefficient}

It would be misleading to emphasize the hump-shaped pattern between growth and inequality measured by the income difference between the two groups because the population share of the rich group decreases with population aging. If the share effect is dominant, then we may observe that the economy wide income distribution is improved.

Since our model economy is a two-class economy, we can calculate the Gini coefficient easily. The income distribution is $w_{t}$ for the poor (a fraction of $1-p$ ) and $(1+\hat{b}) w_{t}$ for the rich $(p)$. The mean income is $(1-p) w_{t}+p(1+\hat{b}) w_{t}=$ $(1+p \hat{b}) w_{t}$ and the mean difference is $2(1-p) p \hat{b} w_{t}$. Therefore the Gini coefficient, denoted by $\gamma$, is given by $(1-p) p \hat{b} /(1+p \hat{b})$. Using (31), we have

$$
\gamma=\frac{p(1-p)}{\beta+p} \frac{1+\alpha_{1}(1-p)}{1+\alpha_{1}(1-p)+\alpha_{2}}
$$

If the level of mortality rate is high, a mortality decline increases the Gini coefficient since the wealth effect dominates the share effect. In the process of population aging, however, the share effect becomes dominant, which decreases the Gini coefficient. Formally we have the following proposition:

Proposition 4 The Gini coefficient has a unique interior maximum in $(0,1)$.

Proof. See Appendix.

We can derive the relationship between the growth rate and the Gini coefficient by combining Propositions 3 and 4 . When the externality is weak $\left(\beta<\beta_{g}\right)$, 
both are hump-shaped with respect to the mortality rate. It implies that the inequality is positively related to the growth rate for a higher and a lower level of mortality rate. The relationship could be negative when the mortality rate is intermediate. Figure 1 shows a locus of $(g(p), \gamma(p))$ when $\beta<\beta_{g}{ }^{13}$ If the externality is significant $\left(\beta>\beta_{g}\right)$, the growth rate increases monotonically with the mortality decline. In this case, the relationship would be first positive and then negative in the process of population aging. Figure 2 illustrates an example when $\beta>\beta_{g}$.

Figure 1. Growth versus Distribution when the externality is weak

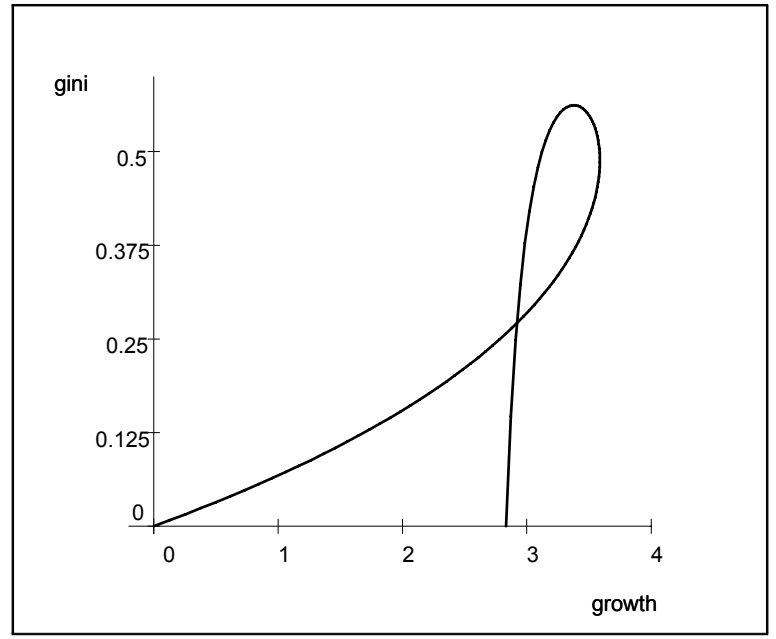

$\alpha_{1}=0.5, \alpha_{2}=0.2, v=0.1, \eta=10$, and $\beta=0.05$.

Figure 2. Growth versus Distribution when the externality is strong

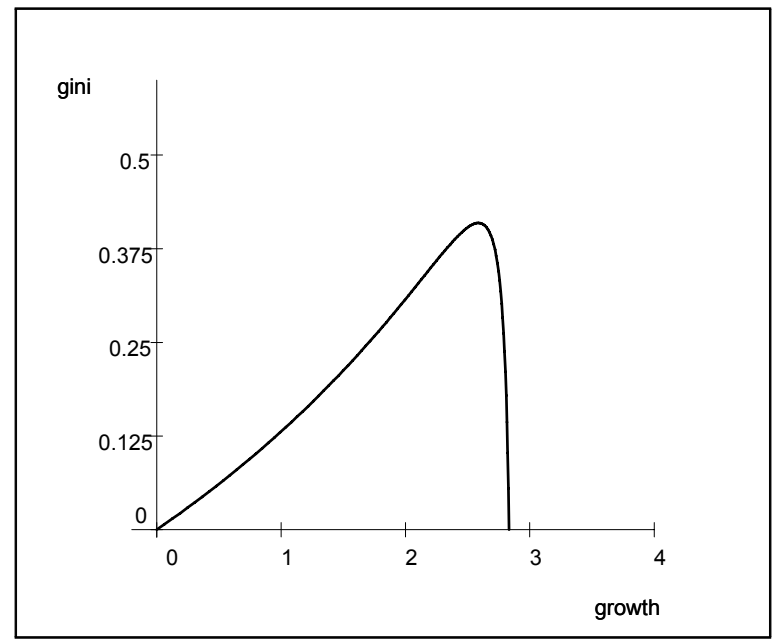

$\alpha_{1}=0.5, \alpha_{2}=0.2, v=0.1, \eta=10$, and $\beta=0.15$.

\footnotetext{
${ }^{13}$ It is assumed that $\alpha_{1}=0.5, \alpha_{2}=0.2, v=0.1, \eta=10$, and $\beta=0.05$. From (35), the critical value is $\beta_{g}=0.122$.
} 


\subsection{Intergenerational inequality}

In order to examine intergenerational inequality, we first derive a criterion for the optimal income distribution based on a Bentham-Lerner social welfare function such as

$$
W_{t}=W\left(N_{t} u_{1}\left(c_{1 t}\right),(1-p) N_{t-1} u_{2}\left(c_{2 t}\right)\right)
$$

where $c_{1 t} \equiv C_{1 t} / N_{t}$ and $c_{2 t} \equiv C_{2 t} /\left[(1-p) N_{t-1}\right]$ stand for per capita young-age and old-age consumption at period $t$, respectively. Maximizing the social welfare subject to the resource constraint, (23), we have the optimality condition for consumption allocation,

$$
\mu_{t} \equiv \frac{W_{1} u_{1}^{\prime}\left(c_{1 t}\right)}{W_{2} u_{2}^{\prime}\left(c_{2 t}\right)}=1
$$

where $W_{i}$ stands for the $i$ th derivative $(i=1,2)$. $\mu_{t}$ stands for the conventional index of intergenerational income distribution. If $\mu_{t}$ is larger (smaller) than one, then the distribution is in favor of the old (young) generation. Further, we specify the social welfare function such as

$$
\begin{aligned}
W & =N_{t} u_{1}+\delta \cdot(1-p) N_{t-1} u_{2} \\
u_{1}(c) & =u_{2}(c)=\ln c
\end{aligned}
$$

$\delta \in(0,1)$ stands for a social discount factor, which may differ from the private discount factor, $\alpha_{1}$. Then we have

$$
\mu_{t}=\frac{1}{\delta} \frac{c_{2 t}}{c_{1 t}}
$$

The distribution is optimal when $c_{2 t} / c_{1 t}=\delta$. From (15), (17), and (21), the index on the BGP is given by

$$
\mu=\frac{\alpha_{1}}{\delta}(1-p) \frac{1+r}{1+g}
$$

The mortality decline affects the inequality index in two ways. First, it directly increases $\mu$. The income distribution moves in favor of the old generation because the marginal value of old-age consumption increases. Second, it indirectly decreases $\mu$ through a change in the growth rate. When the growth rate increases, the present value of old-age consumption decreases. Therefore the income distribution moves in favor of the young generation. It can be shown that the net effect is positive because, with (26), we can transform (37) into

$$
\mu=\frac{\alpha_{2}}{v \delta} \hat{b}
$$

It is the accidental bequest that plays a critical role in intergenerational inequality. From Proposition 2, we know $d \hat{b} / d p<0$ thus $d \mu / d p<0$. The mortality decline skews consumption allocation in favor of the old generation. The trend of population aging makes dissavers rich and savers poor. Combining this with Proposition 3, we have a positive relationship between growth and inequality in the earlier phases, and the relationship can be negative in the process of population aging. 


\section{Conclusions}

Theoretically, this paper has three contributions to the related literature. First, it shows that the growth rate may be hump-shaped with respect to the mortality rate when the bequest is accidental and the externality is weak. It contrasts with the results obtained in the models where bequests are motivated by pure or impure altruism. The reason is that the accidental bequest makes the initial asset heterogeneous and that the mortality decline has a distributional effect on aggregate savings. Second, compared with the literature on the accidental bequest, this paper endogenizes the fertility rate. Since the decreased fertility rate has a positive impact on the growth rate of per capita income, it can encourage economic growth even if the saving rate decreases. Specifically, if the externality is intermediate, $\beta \in\left(\beta_{g}, \beta_{s}\right)$, then the mortality decline increases the growth rate although it decreases the saving rate. Third, the inter- and intragenerational inequalities are considered in the context of population aging. The bequest wage ratio, $\hat{b}$, plays a critical role in the inequalities. The mortality decline increases $\hat{b}$, which implies that the trend of population aging worsens both inter- and intra- generational inequalities. When the growth rate is humpshaped, this implies that the relationship between growth and inequality is at first positive and then negative in the process of population aging.

The policy implications of the paper should be treated cautiously as it examines the growth rate and income distribution, but not the welfare. Nevertheless, it may alert us to the rather optimistic standpoint found in related literature. In the process of population aging, some developed countries could find themselves in a stagnant and inequitable situation in the near future. If the governments are concerned about this, this paper suggests they should carry out a transfer policy in favor of the younger generation who have a higher propensity to save and thus contribute to capital formation. 


\section{Appendix}

[Proof of Proposition 2] Differentiating (32) with respect to $p$, we have

$$
\frac{d \hat{s}}{d p}=\frac{\alpha_{1}\left\{(1-p)\left[1+\alpha_{1}(1-p)\right]-(\beta+p)\right\}}{\beta\left[1+\alpha_{1}(1-p)\right]^{2}}
$$

We know

$$
\begin{aligned}
& \left.\frac{d \hat{s}}{d p}\right|_{p=1}=-\frac{(1+\beta) \alpha_{1}}{\beta}<0 \\
& \left.\frac{d \hat{s}}{d p}\right|_{p=0}=\frac{\alpha_{1}\left(1+\alpha_{1}-\beta\right)}{\beta\left(1+\alpha_{1}\right)^{2}}
\end{aligned}
$$

Since the numerator of $d \hat{s} / d p$ is a quadratic function of $p$ with a positive coefficient of the quadratic term, the saving rate has an interior maximum if and only if $d \hat{s} /\left.d p\right|_{p=0}>0$, that is,

$$
\beta<1+\alpha_{1}
$$

[Proof of Proposition 3] From (33), we know

$$
1+g=G(p)=\frac{\alpha_{1}}{\alpha_{2}} \eta v \phi(p)
$$

where

$$
\begin{aligned}
& \phi(p)=(1-p) \varphi(p) \\
& \varphi(p)=1+\frac{\alpha_{2}(\beta+p)}{\beta\left[1+\alpha_{1}(1-p)\right]}
\end{aligned}
$$

Note that $G(0)>0$, which contrasts with Foster (1999) and Cipriani (2000). First, we show that the growth rate is concave with respect to $p$, that is, $G^{\prime \prime}<0$. Then, we show that $G^{\prime}(0)>0$ is equivalent to (35). Since $G(1)=0$ and $G(0)>0, g$ has an interior maximum if and only if the condition (35) is satisfied because of the concavity.

We know

$$
\begin{aligned}
\phi^{\prime}(p) & =-\varphi(p)+(1-p) \varphi^{\prime}(p) \\
\phi^{\prime \prime}(p) & =-2 \varphi^{\prime}(p)+(1-p) \varphi^{\prime \prime}(p)
\end{aligned}
$$

and

$$
\begin{aligned}
\varphi^{\prime}(p) & =\frac{\alpha_{2}\left(1+\alpha_{1}+\beta \alpha_{1}\right)}{\beta\left[1+\alpha_{1}(1-p)\right]^{2}}>0 \\
\varphi^{\prime \prime}(p) & =\frac{2 \alpha_{1} \varphi^{\prime}(p)}{1+\alpha_{1}(1-p)} .
\end{aligned}
$$

First, we have

$$
\phi^{\prime \prime}(p)=-\frac{2 \varphi^{\prime}(p)}{1+\alpha_{1}(1-p)}<0
$$


which implies that $G$ is concave.

Second, we have

$$
\phi^{\prime}(0)=\frac{\alpha_{2}}{\beta\left(1+\alpha_{1}\right)}+\frac{\alpha_{1} \alpha_{2}}{\left(1+\alpha_{1}\right)^{2}}-\left(1+\frac{\alpha_{2}}{1+\alpha_{1}}\right)
$$

Thus, $\phi^{\prime}(0)>0$ is equivalent to (35).

[Proof of Proposition 4] From (36), we have $\gamma=(1-p) f_{1}(p) f_{2}(p)$, where

$$
\begin{aligned}
& f_{1}(p)=1-\frac{\beta}{\beta+p} \\
& f_{2}(p)=1-\frac{\alpha_{2}}{1+\alpha_{1}(1-p)+\alpha_{2}}
\end{aligned}
$$

First, we have $\gamma(0)=\gamma(1)=0$.

Second, we have $f_{1}^{\prime}>0, f_{1}^{\prime \prime}<0, f_{2}^{\prime}<0$, and $f_{2}^{\prime \prime}<0$ for $p \in[0,1]$, and

$$
\begin{aligned}
\gamma^{\prime}(p) & =-f_{1} f_{2}+(1-p)\left(f_{1}^{\prime} f_{2}+f_{1} f_{2}^{\prime}\right) \\
\gamma^{\prime \prime}(p) & =-2\left(f_{1}^{\prime} f_{2}+f_{1} f_{2}^{\prime}\right)+(1-p)\left(f_{1}^{\prime \prime} f_{2}+2 f_{1}^{\prime} f_{2}^{\prime}+f_{1} f_{2}^{\prime \prime}\right)
\end{aligned}
$$

Since $\gamma(p)$ is continuous in $[0,1]$ and $\gamma(p)>0$ for $\forall p \in(0,1)$, there exists at least one solution $p^{*} \in(0,1)$ such that it maximizes $\gamma$. The necessary condition, $\gamma^{\prime}\left(p^{*}\right)=0$, requires

$$
f_{1}^{\prime} f_{2}+f_{1} f_{2}^{\prime}=\frac{f_{1} f_{2}}{1-p^{*}}>0
$$

which implies $\gamma^{\prime \prime}\left(p^{*}\right)<0$. Therefore we know that $\gamma$ does not have any local minimums in $(0,1)$. It proves the uniqueness of $p^{*}$. 


\section{Acknowledgment}

I am grateful to Frank Cowell, Akira Yakita, Hikaru Ogawa, Makoto Hirazawa, Yuji Nakayama, Akira Momota, Yoshinao Sahashi, and workshop participants at Chukyo University and Osaka Prefecture University for helpful comments on an earlier version of the paper. The research is supported by grants from the Japan Society for the Promotion of Science (No.13630023) and the Pache Research Subsidy I-A-2 (Nanzan University, 2005). All errors are of course mine.

\section{References}

[1] Abel, Andrew B. (1985) Precautionary saving and accidental bequests, American Economic Review 75, 777-791.

[2] Aghion, Philippe, and Patrick Bolton (1992) Distribution and growth in models of imperfect capital markets, European Economic Review 36, 603611.

[3] Arrow, Kenneth J. (1962) The economic implications of learning by doing, Review of Economic Studies 29, 155-173.

[4] Atkinson, Anthony B. (1999) The distribution of income in the UK and OECD countries in the twentieth century, Oxford Review of Economic Policy $15,56-75$.

[5] Banerjee, Abhijit V., and Esther Duflo (2000) Inequality and growth: what can the data say?, NBER Working Paper No. 7793.

[6] Bénabou, Roland (1996) Inequality and growth, in Bernanke, Ben S., and Julio J. Rotemberg, eds., NBER Macroeconomics Annual 1996, Cambridge, MIT Press, 11-74.

[7] Bowles, Samuel, and Herbert Gintis (2002) The inheritance of inequality, Journal of Economic Perspectives 16, 3-30.

[8] Castañeda, Ana, Díaz-Giménez, Javier, and José-Víctor Ríos-Rull (2003) Accounting for the U.S. earnings and wealth inequality, Journal of Political Economy 111, 818-857.

[9] Checchi, Daniele, and Cecilia García-Peñalosa (2004) Risk and the distribution of human capital, Economics Letters 82, 53-61.

[10] Cipriani, Giam Pietro (2000) Growth and unintended bequests, Economics Letters 68, 51-53.

[11] Dahan, Momi, and Daniel Tsiddon (1998) Demographic transition, income distribution, and economic growth, Journal of Economic Growth 3, 29-52.

[12] De Nardi, Mariacristina (2005) Wealth inequality and intergenerational links, forthcoming in Review of Economic Studies.

[13] Ehrlich, Isaac, and Francis T. Lui (1991) Intergenerational trade, longevity, and economic growth, Journal of Political Economy 99, 1029-1059. 
[14] Fuster, Luisa (1999) Effects of uncertain lifetime and annuity insurance on capital accumulation and growth, Economic Theory 13, 429-445.

[15] Galor, Oded, and Daniel Tsiddon (1997) The distribution of human capital and economic growth, Journal of Economic Growth 2, 93-124.

[16] Galor, Oded, and David N. Weil (1998) Population, technology, and growth: from the Malthusian regime to the demographic transition, NBER Working Paper No. 6811.

[17] Galor, Oded, and David N. Weil (2000) Population, technology, and growth: from Malthusian stagnation to the demographic transition and beyond, American Economic Review 90, 806-828.

[18] Galor, Oded, and Hyoungsoo Zang (1997) Fertility, income distribution, and economic growth: theory and cross-country evidence, Japan and the World Economy 9, 197-229.

[19] Galor, Oded, and Joseph Zeira (1993) Income distribution and macroeconomics, Review of Economic Studies 60, 35-52.

[20] Grossman, Gene M., and Noriyuki Yanagawa (1993) Asset bubbles and endogenous growth, Journal of Monetary Economics 31, 3-19.

[21] Hazan, Moshe, and Binyamin Berdugo (2002) Child labour, fertility, and economic growth, Economic Journal 112, 810-828.

[22] Huggett, Mark (1996) Wealth distribution in life-cycle economies, Journal of Monetary Economics 38, 469-494.

[23] Huggett, Mark, and Gustavo Ventura (2000) Understanding why high income households save more than low income households, Journal of Monetary Economics 45, 361-397.

[24] Kalemli-Ozcan, Sebnem, Ryder, Harl E., and David N. Weil (2000) Mortality decline, human capital investment, and economic growth, Journal of Development Economics 62, 1-23.

[25] Kotlikoff, Laurence J., and Lawrence H. Summers (1981) The role of intergenerational transfers in aggregate capital accumulation, American Economic Review 89, 706-732.

[26] Lucas, Robert E., Jr. (1988) On the mechanics of economic development, Journal of Monetary Economics 22, 3-42.

[27] OECD (1998) Maintaining the prosperity in an ageing society, Paris, France.

[28] Owen, Ann L., and David N. Weil (1998) Intergenerational earnings mobility, inequality and growth, Journal of Monetary Economics 41, 71-104.

[29] Romer, Paul M. (1986) Increasing returns and long-run growth, Journal of Political Economy 94, 1002-1037.

[30] Yakita, Akira (2001) Uncertain lifetime, fertility and social security, Journal of Population Economics 14, 635-640. 
[31] Zhang, Jie, and Junsen Zhang (2001) Longevity and economic growth in a dynastic family model with an annuity market, Economics Letters 72 , 269-277.

[32] Zhang, Jie, Zhang, Junsen, and Ronald Lee (2003) Rising longevity, education, savings, and growth, Journal of Development Economics 70, 83-101.

[33] Zhang, Junsen, and Junxi Zhang (2001) Bequest motives, social security, and economic growth, Economic Inquiry 39, 453-466. 